\title{
Evaluating shear bond strength efficacy of seventh and eighth generation bonding agents
} (an in vitro study)

\author{
Hidayat Ababakr Khudhur ${ }^{(1)}$; Diyar Khalid Bakr ${ }^{(1)} ;$ Sazan Sherdl Saleem ${ }^{(2)}$; Sohela Fakher Mahdi ${ }^{(1)}$
}

Background and Objectives: The most important purpose of dental adhesives is to offer retention to composite fillings or composite cements. The most frequently applied laboratory parameter to evaluate the effectiveness of dentin bonding agents is shear bond strength. The aim of this study is to introduce the 8th generation of bonding to our country's dentists and investigating the manufacturer's claim in this research, and compare the shear bond strength of two types of systems.

Material and Methods: Thirty freshly extracted maxillary premolars were collected. After preparation, the samples were randomly divided into two groups of fifteen and each group was treated with a different bonding agent. In group A, 15 specimens were treated by Gluma Bond Universal (Kulzer, Hanau, Germany). In group B, 15 specimens were treated by LuxaBond Universal (DMG, Hamburg, Germany). O-Light Curing Light unit (Woodpecker, Guilin, China) used for polymerization of both bonding systems. Composite (Beautifil Injectable X, Shofu Inc, Kyoto, Japan) cylinders were afterwards placed on the bonded surfaces using an elastic mold and were light-cured. To measure the shear bond strength of the specimens a universal material tester was used. Descriptive Statistics and One Sample test was conducted for statistical analysis.

Results: The highest strength was seen in the 8th generation bonding agent (LuxaBond Universal (DMG, Hamburg, Germany). A highly significant difference $(p<0.000)$ was found between the seventh and eighth-generation bonding groups.

Conclusion: The eighth-generation bonding agent showed higher mean bond strength than the seventh.

\footnotetext{
(1) Department of Conservative Detistry, College of Dentistry, Hawler Medical University, Erbil, Iraq.

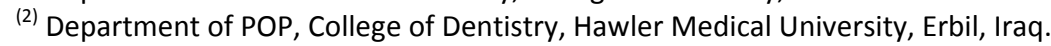

\section{Introduction}

The introduction of tooth-colored composite represented a step forward in the development of the adhesive system. Adhesion to dental tissue is a major necessity before the insertion of tooth-colored restorative material. ${ }^{1}$ The main goal of dental adhesives is to offer retention to composite fillings or composite cements. Along with withstanding mechanical forces, and specifically shrinkage stress from the lining composite, a decent adhesive also should be able to stop leakage along the restoration's margins. ${ }^{2}$

Dental adhesive systems have been developing through several generations with which we have witnessed many changes in the chemistry, mechanism of operation, the number of steps involved in the procedure, the technique of application, and their clinical effectiveness. The availability of dentin adhesives is in many systems like three-step, two-step, or single-step systems, which wholly depends on how the steps of etching, priming, and bonding to the tooth surface are accomplished. ${ }^{3}$ Dentists assumed that the fourth 
generation of dentin bonding system was fairly complex and time-consuming to use, and called for easier solutions. The fifth generation of bonding agents was the first simplification, systems in which the primer and adhesives were mixed together and delivered as a single system. Dentists sought even simpler systems which is why two more systems were developed, comprising of an acidic primer and a bonding resin denoted as a sixth-generation adhesive, and another in which the etchant, primer, adhesive are joined into one single delivery system manifested as the seventh generation of adhesive systems. Total etch adhesive can present as two-step adhesives or threestep adhesives. ${ }^{4}$

Existing adhesion strategies are determined by how dental adhesives interact with the smear layer and are assembled into two basic categories: Etch -and-rinse (ER) strategy and self-etch (SE) strategy. ER strategy involves total removal of the smear layer and superficial hydroxyapatite through etching with a separate acid gel (commonly phosphoric acid) ${ }^{5}$ afterward infiltration of adhesive monomers that permeate the microporosities creating hybrid tissue referred to as the resin-dentin inter-diffusion zone or the "Hybrid Layer". ${ }^{6}$ Opposingly, the SE approach makes the smear layer permeable without totally getting rid of it. This does not necessitate a distinct phosphoric acidetch step as acidic adhesive monomers are used to partially dissolve the smear layer and demineralize the underlying dentin/ enamel while infiltration is attained concurrently. ${ }^{7}$ The latest of these is "Universal" or "Multi-mode" adhesives which offer dentists the choice of choosing the adhesion strategy - ER, SE, or an alternative "selective enamel etching" (SEE) strategy, which is a mixture of ER strategy on enamel and SE strategy on dentin. Furthermore, these adhesives deliver the flexibility of use for bonding various direct and indirect restorative materials such as composite resins, glass-matrix ceramics, zirconia, and metals. ${ }^{14,18,19,20}$ Still there isn't a formal definition for what meets the requirements as a Universal Adhesive (UA), literature defines it as a single-bottle, nomix adhesive system that accomplishes equally well with any adhesion strategy and bonds effectively to tooth structure plus to different direct and indirect restorative materials. ${ }^{9}$

Two significant properties of dentin bonding systems that are really effective in the durability of composite restorations are shear bond strength and microleakage. ${ }^{10}$ Shear bond strength is the most regularly applied laboratory parameter to assess the effectiveness of dentin bonding agent. ${ }^{11}$ Meanwhile the eighth generation bonding has just been familiarized recently and there are few studies about it, intending to introduce this generation of bonding to our country's region and investigate manufacturer's claim in this research, we aim to compare the shear bond strength of two types of systems.

\section{Materials and Methods}

Thirty freshly extracted non-carious maxillary premolars were collected which were extracted for orthodontic purpose. The teeth with the aids of dental surveyor were embedded vertically in cold-cure acrylic resin with the help of a ready-made PVC house pipe of dimension 1 (width) $\times 2$ $\mathrm{cm}$ (height) (Figure 1, A). The occlusal surface of each specimen was cut and completely exposed to the dentin with a diamond bur (NTI, Kahla GmbH, Germany), and cooled continuously by water spray to prevent heat (Figure 1, B). After that, the dentin surfaces of each specimen abraded for about 20 seconds with silicone paper discs to create a uniform smear layer. ${ }^{10}$ The samples were stored in distilled water until used for bonding. ${ }^{12}$ After preparation, the samples were randomly divided into two groups of fifteen and each group was treated with a different bonding agent as shown in (Table 1). In group $A, 15$ specimens were treated 
Table 1. Bonding agents used in this study.

\begin{tabular}{|c|c|c|c|}
\hline $\begin{array}{c}\text { Generation of } \\
\text { bonding }\end{array}$ & Trade name & Manufacture & Composition \\
\hline $\begin{array}{l}\text { Group A: } \\
\text { Seventh- } \\
\text { generation }\end{array}$ & $\begin{array}{l}\text { Gluma Bond } \\
\text { Universal }\end{array}$ & $\begin{array}{c}\text { Kulzer, Hanau, } \\
\text { Germany }\end{array}$ & $\begin{array}{l}\text { 4-MET acid, methacrylate monomer, } \\
\text { acetone, 10-MDP, and water }\end{array}$ \\
\hline $\begin{array}{l}\text { Group B: } \\
\text { Eighth- } \\
\text { generation }\end{array}$ & $\begin{array}{l}\text { LuxaBond } \\
\text { Universal } \\
\text { A and B }\end{array}$ & $\begin{array}{l}\text { DMG, } \\
\text { Hamburg, } \\
\text { Germany }\end{array}$ & $\begin{array}{l}\text { Bond A: Resin matrix (HEMA, bis-GMA, } \\
\text { MDP) approx. } 97 \% \text {, catalyst, stabilizer, } \\
\text { additives. } \\
\text { Bond B: Ethanol approx. } 57 \% \text {, water } \\
\text { approx. } 35 \% \text {, catalyst (benzoyl peroxide), }\end{array}$ \\
\hline
\end{tabular}

Table 2. Manufacturer's instructions for bonding agent application.

\begin{tabular}{|c|c|}
\hline LuxaBond Universal & GLUMA Bond Universal \\
\hline $\begin{array}{l}\text { Mix one drops each of bond } A \text { and bond } B \text { in } \\
\text { a mixing pad in a 1:1 ratio for approx. } 5 \\
\text { seconds. } \\
\text { Apply a layer of the bond mix onto the } \\
\text { preparation using a micro brush and work } \\
\text { into the tooth structure for } 20 \text { seconds. } \\
\text { Direct a stream of air at the material for } 10 \\
\text { seconds } \\
\text { Apply another layer of the bond mix onto the } \\
\text { preparation using a micro brush and work } \\
\text { into the tooth structure for } 20 \text { seconds. } \\
\text { Direct a stream of air at the material for } 10 \\
\text { seconds } \\
\text { Polymerise LuxaBond for } 20 \text { seconds }\end{array}$ & $\begin{array}{l}\text { Drop GLUMA Bond Universal into the mixing } \\
\text { well and use immediately (within } 3 \text { minutes). } \\
\text { Use the applicator tip or brush to apply } \\
\text { GLUMA Bond Universal to the entire surface } \\
\text { of the tooth } \\
\text { Gently rub in the adhesive for } 20 \text { seconds. } \\
\text { - } \\
\text { Air dry carefully with a gentle oil-free air flow } \\
\text { until the adhesive film no longer moves. } \\
\text { The surface must be visibly glossy both after } \\
\text { applying GLUMA Bond Universal and also } \\
\text { after evaporation of the solvent. } \\
\text { Polymerise GLUMA Bond I for } 10 \text { seconds }\end{array}$ \\
\hline
\end{tabular}

Acrylic mold was fixed on bench vice then composite (Beautifil Injectable X, Shofu Inc, Kyoto, Japan) cylinders were afterwards placed on the bonded surfaces using an elastic mold of dimension $2 \mathrm{~mm}$ diameter $\times$ $2 \mathrm{~mm}$ height 13 and were light-cured. All samples rechecked for dimension by digital vernier (Figure 1; C, D, E \& F). Prior and between each light cure polymerization stages light output was monitored using a radiometer (Hilux Curing Light Meter, Benlioglu Dental Inc.) to ensure accurate 

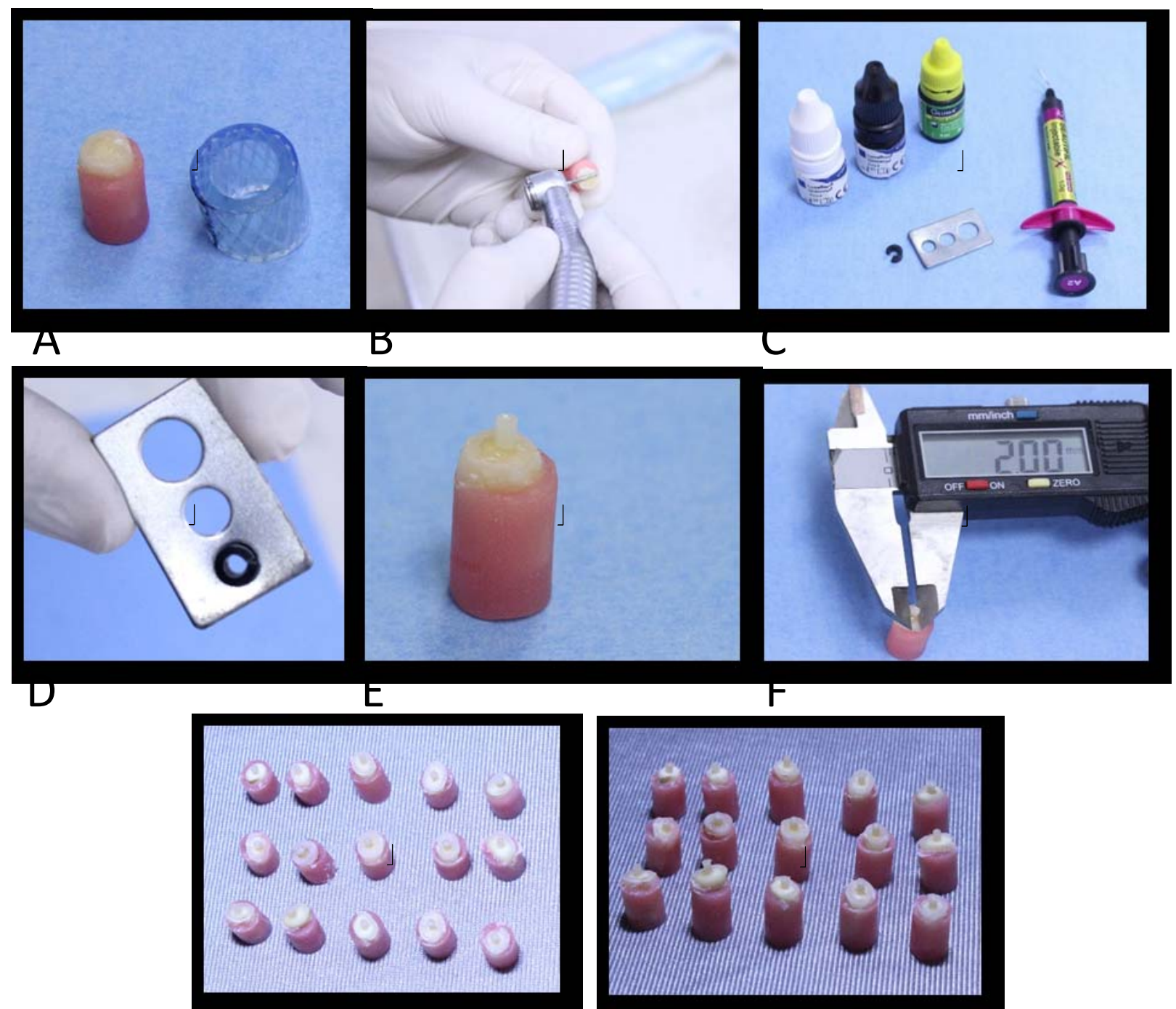

A

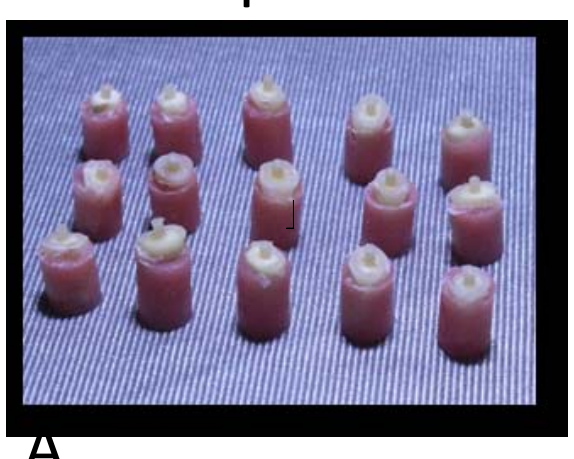

Figure 1: Steps of sample fabrication. (A) Teeth embedded vertically in cold-cure acrylic resin with aid of ready-made PVC house pipe; (B) Cutting occlusal surface with a diamond bur; (C, D, E, F) Composite cylinders fabrication; (G,H) Sample collection.
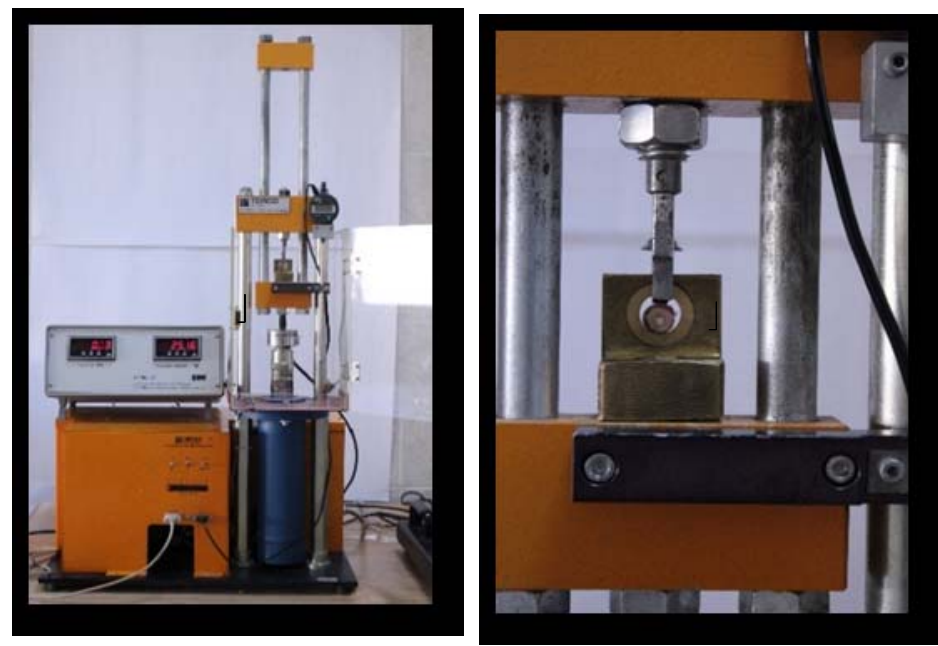

Figure 2: shear bond strength measurement device (universal material tester). 


\section{Results}

The descriptive parameters of the two experimental groups are presented in Table 1. The mean shear bond strength value for seventh generation adhesive was 6.3960 Mpa and eighth generation adhesive was 15.0950 Mpa respectively. The highest strength was seen in the 8th generation bonding agent (LuxaBond Universal (DMG, Hamburg, Germany).
One-Sample T-Test was performed to determine any statistically significant differences in the shear bond strengths between the groups compared in this study. The One-sampled T-Test showed a highly statistically significant difference $(\mathrm{p}<$ 0.000 ) between the seventh and eighth generation bonding groups as seen in Table 2 .

Table 1: differences in the shear bond strengths between the groups

\begin{tabular}{|c|c|c|c|c|c|}
\hline Bonding generation & $\mathbf{N}$ & Minimum & Maximum & Mean & Std. Deviation \\
\hline Seventh & 15 & 3.82 & 8.91 & 6.3960 & 1.72183 \\
\hline Eighth & 15 & 11.14 & 19.11 & 15.0950 & 2.48756 \\
\hline
\end{tabular}

Table 2: difference between the seventh and eighth generation bonding groups

\begin{tabular}{|c|c|c|c|c|c|c|}
\hline \multirow{3}{*}{$\begin{array}{c}\text { Bonding } \\
\text { generation }\end{array}$} & \multicolumn{6}{|c|}{ Test Value $=0$} \\
\hline & \multirow{2}{*}{$\mathbf{t}$} & \multirow{2}{*}{ df } & \multirow{2}{*}{ Sig. (2-tailed) } & \multirow{2}{*}{$\begin{array}{c}\text { Mean } \\
\text { Difference }\end{array}$} & 95\% Confidence Interval of the & \multirow[t]{2}{*}{ Difference } \\
\hline & & & & & Lower & \\
\hline Seventh & 11.747 & 9 & .000 & 6.39600 & 5.1643 & 7.6277 \\
\hline Eighth & 19.189 & 9 & .000 & 15.09500 & 13.3155 & 16.8745 \\
\hline
\end{tabular}

\section{Discussion}

Shear bond strength is an essential characteristic of dentin bonding systems that is highly effective on the durability of composite restorations. Dentin bonding systems are used to bond the composite to the teeth, and poor bonding systems are a solitary problem in dentistry, particularly prosthetic and restorative treatments, which result in failures. Adverse consequences such as discoloration of the teeth because of recurrent caries around the restoration and eventually loss of repair are related to the poor bonding and the trouble of applying dentin bonding systems. ${ }^{15}$ Novel adhesive systems have significantly decreased the necessity for extensive tooth preparation, so allowing more conservative preparation, decreased dependence on micromechanical retention, and reduced removal of unsupported enamel. ${ }^{16}$ Many factors can be effective in the results of shear bond strength test for example the stages and conditions of the test, the type of tooth tested, and the way teeth are selected and stored, the depth of dentin and enamel assessed, the type of measuring device and type of manufacturer adhesive. Several systems have been presented up to now that has always pursued to make the clinical process easier by manufacturers in the newer types, but due to the significance of enamel and dentin differences, the simplification of the clinical procedure can bring about reduced dentin bond strength and increased micro leakage. This noticeably happened in the 7th generation bonding's, which lessened dentists' interest in selfetching techniques. ${ }^{10}$

The bonding agents used in this study are 
self-etch bonding agents, i.e., Gluma Bond Universal (Kulzer) which is a seventhgeneration dentin bonding agent, and LuxaBond Universal DC (DMG) which is eighth-generation dentin bonding. Gluma Bond Universal (Kulzer)is a light-cure adhesive that is used for both direct and indirect applications. It is a one-step, onecoat application for a quick 30-second working time, i.e., application for 20 seconds then light curing for 10 seconds, while LuxaBond Universal DC (DMG) is a dual-curing adhesive, i.e., chemical and light cure. It has the advantage of chemical curing in areas inaccessible to light curing. It is also a one-step, but the multi-coat application for a 70-second working time. In this study, the highest mean shear bond strength was observed in eighth-generation (LuxaBond Universal) dentin adhesives compared to seventh generation adhesives. The morphological features of the hybrid layer formed by self-etch adhesives are greatly influenced by the capability of their functional monomers to demineralize the dental substrate. Therefore, in line with their acidity or etching aggressiveness, self-etch adhesives can be classified as strong $(\mathrm{pH} \leq 1)$, intermediate $(\mathrm{pH}=1.5)$ and mild $(\mathrm{pH} \geq 2) .{ }^{17}$ Subsequently, the self-etch adhesives are not as hostile as the phosphoric acid gel in etch-and-rinse adhesives, most do not take away the smear layer. ${ }^{18}$ Complete dissolution of nearly all hydroxyapatite crystals are caused by strong self-etch adhesives. The fundamental bonding mechanism is mainly diffusionbased and has been often recognized with rather low bond strength values. Generally, mild self-etch systems, have a $\mathrm{pH}$ of about 2 and demineralize dentin merely to a depth of one micro meter. The superficial demineralization to some extent retains the residual hydroxyapatite still attached to collagen. ${ }^{19}$ LuxaBond can be classified as an aggressive, as this material has a very low $\mathrm{pH}$ (LuxaBond $\mathrm{pH}=1.2$ ) when compared to Gluma Bond Universal $(\mathrm{pH}=1.8)$. This might be why this material showed the highest bond strength.
The fact that the chemical composition of adhesive systems governs their clinical success has been conveyed by many studies. $^{20}$ Showed that ethanol has a stiffening effect on demineralized collagen, this feature may also explain why ethanol can maintain wide interfibrillar spaces after evaporation of the solvent. The available one-bottle total-etch adhesive systems turn out to be common because of easy handling, useful and simpler to utilize than multi- step adhesive systems, instead of because of better bonding. ${ }^{21}$ Dentin bonding is enhanced in the presence of high-vapor pressure organic solvents for hydrophilic bonding systems. These solvents enable deeper and more thorough penetration of monomers into dentin to increase micromechanical retention. ${ }^{22}$ It has been documented that to avoid the collapse of the exposed collagen network, implementing a moist bonding protocol is tremendously vital in acetone-based bonding systems because of the water-chaser effect of acetone. ${ }^{23}$ Alternatively, the excess of water can intensely affect acetone-based shear bond strength to dentin. ${ }^{24}$ Although this study used an acetone-based one and an ethanolbased one, the narrow window of opportunity to achieve adequate dentin bonding with acetone-based systems may explain the fact that the acetone-based onebottle system yielded lower shear bond strength means to dentin than the ethanolbased system. These findings are consistent with those of previous studies. ${ }^{25}$ So another possible explanation for the low shear bond strength of Gluma Bond Universal to dentin related with acetone-based adhesive systems is its high percentage of acetone nearly to $70 \%$ in the system. Controlling moisture of the root canal dentine following post-space preparation and etching is really hard to achieve. ${ }^{26}$ Procedures for adhesive luting to root dentin have been improved according to the "ethanol wet bonding" strategy that was presented as a pre-treatment for etch-andrinse (ER) adhesives facilitate the evaporation of residual water on coronal dentin and stabilizing the etched collagen 
matrix for resin infiltration. ${ }^{27}$ The presentation of universal adhesives inside the root canal has only been studied in recent times. Until now, researchers have discovered the effects of dentin moisture and application mode ${ }^{28}$ While, the universal adhesive LuxaBond Universal revealed higher bond strength than RelyX Unicem 2, both profited from root canal pre-treatment using ethanol. ${ }^{29}$

Manufacturer's instructions of LuxaBond Universal DC (DMG) material recommend the application of an extra layer of LuxaBond. Different in vitro ${ }^{30,31}$ and in vivo studies $^{32,33}$ have displayed that the application of an additional layer enhances the performance of one-step Self-adhesives, given that this is a layer with a hydrophobic nature. This additional layer combines nonsolvated hydrophobic monomers at the bonding interface, which reduces the relative concentration of solvents retained and nonreacted monomers in the adhesive layer, ${ }^{34}$ making it less permeable ${ }^{35}$ and not as much prone to the effects of degradation over time. ${ }^{36}$ That's why the eighthgeneration dentin adhesives have higher bond strength in comparison with seventh generation adhesives.

Considering that dentin is a challenging substrate for adhesion and that the Gluma Bond Universal system is comprised of a heterogeneous composition that mixes various components into the same solution (e.g., acidic and non-acidic monomers, solvents, initiators, and silane), the combination of these factors may have probably decreased the bonding ability of Gluma Bond Universal to dentin. on the other hand, LuxaBond has a less complex composition than Gluma Bond Universal, thus allowing satisfactory adhesion, which is agreed by several previous studies. ${ }^{37}$ In our study, UTM Instron was used, which is conventionally popular for evaluating the adhesive ability of adhesive/restorative materials, ${ }^{38}$ and it was also used by Joseph et al. ${ }^{39}$ to compare bond strength of sixth(Clearfil SE), seventh- (Adper Easy One), and eighth (Futurabond DC) generation dentin bonding agents and inferred that the highest bond strength was seen in eighthgeneration dentine bonding agent followed by seventh-generation that was also seen in our study.

\section{Conclusion}

Within the limitations of the present in vitro study, it can be concluded that the eighthgeneration bonding agent showed higher mean bond strength to dentin than the seventh. The highest value was shown by LuxaBond Universal but it is a little timeconsuming.

\section{Conflict of Interest}

The authors reported no conflict of interests.

\section{References}

1. Dhawan R, Indira R, Dhawan S. A comparative evaluation of tensile bond strength and scanning electron microscopic study of three generation bonding agents. An in-vitro study. J Conserv Dent. 2005; 8: 8-18.

2. Opdam NJ, Loomans BA, Roeters FJ, Bronkhorst EM. Five-year clinical performance of posterior resin composite restorations placed by dental students. J Dent 2004;32(5):379-83.

3. Ravikumar N, Shankar P, Indira R. Shear Bond Strength of two dentin Bonding Agents with two desensitizers. J Conserv Dent 2011;14(3):247251. DOI: $10.4103 / 0972-0707.85802$.

4. Chauhan U, Dewan R, Goyal NG. Comparative Evaluation of Bond Strength of Fifth, Sixth, Seventh, and Eighth Generations of Dentin Bonding Agents: An In Vitro Study. Journal of Operative Dentistry \& Endodontics. 2020 Dec;5 (2):69-73.

5. Perdigão J. New developments in dental adhesion. Dent Clin N Am 2007;51(2):333-357. viii.

6. Nakabayashi N, Kojima K, Masuhara E. The promotion of adhe- sion by the infiltration of monomers into tooth substrates. J Biomed Mater Res 1982;16(3):265-273.

7. Hanabusa M, Mine A, Kuboki T, Momoi Y, Van Ende A, Van Meerbeek B, De Munck J. Bonding effectiveness of a new 'multi- mode' adhesive to enamel and dentine. J Dent 2012;40(6): 475484.

8. Van Meerbeek B, Frankenberger R. Editorial: What's next after "universal" adhesives, "bioactive" adhesives? J Adhes Dent 2017; 19 (6):459-460. 
9. Matos AB, Trevelin LT, Silva B, Francisconi-DosRios LF, Siriani LK, Cardoso MV. Bonding efficiency and durability: Current possibilities. Braz Oral Res 2017;31(suppl 1):e57.

10.Shafigh, E., Mahdavi, M. R., Nasiri, R. Evaluation and Comparison of Micro Shear of 5th, 7th and 8th Generation Bonding Agents in Dentin (In Vitro Study). Arch Pharma Pract 2020;11(S1):14550

11.Craig RG. Bonding of dental substrates. Craig Restorative dental materials. 10th ed., Mosby Inc; 2002.

12.Standardization IOF. ISO/Technical specifications 11405: Dentistry - Testing of adhesion to tooth structurel 2015

13.Chauhan U, Dewan R, Goyal NG. Comparative Evaluation of Bond Strength of Fifth, Sixth, Seventh, and Eighth Generations of Dentin Bonding Agents: An In Vitro Study. J Oper Dent Endod 2020;5(2):69-73.

14.Paul J, Chakravarthy Y, Kumar S, Rahna R. Comparative evaluation of the bonding efficacy of sixth, seventh and eighth generation bonding agents: an in vitro study. International research journal of pharmacy. 2013 Oct 13;2(9):143-7.

15. Reifeis $P$, Cochran M, Moore B. An in vitro shear bond strength study of enamel/dentin bonding systems on enamel. Operative dentistry. 1995;20:174-.

16.Sturdevant's. Art and science of operative dentistry. Fundamental Concept of Enamel and Dentin Adhesion. 6th ed., Elsevier; 2011. 179202.

17.De Munck J, Van Meerbeek B, Vargas M, et al. One day bonding effectiveness of new self-etch adhesives to bur-cut enamel and dentin. Oper Dent 2005;30:39-49.

18.Jorge Perdigao. New developments in dental adhesion. Dent Clin North Am 2007; 51(2): 33357. http://dx.doi.org/10.1016/ j.cden.2007.01.001 PMid:17532916

19.Shirai K, De Munck J, Yoshida Y, Inoue S, Lambrechts $P$, Suzuki $K$ et al. Effect of cavity configuration and aging on the bonding effectiveness of six adhesives to dentin. Dent Mater 2005; 21(2): 110-24. Carvalho RM, Mendonca JS, Santiago SL, Silveira RR, Garcia FC, Tay FR, et al. Effects of HEMA/solvent combinations on bond strength to dentin. J Dent Res 2003;82(8):597-601.

20.Frankenberger $R$, Kramer $N$, Petschelt $A$. Technique sensitivity of dentin bonding: Effect of application mistakes on bond strength and marginal adaptation. Oper Dent 2000;25:32430.

21.Maciel KT, Carvalho RM, Ringle RD, Preston CD,
Russell CM, Pashley DH. The effects of acetone, ethanol, HEMA, and air on the stiffness of human decalcified dentin matrix. J Dent Res 1996;75:1851-58.

22.Perdigão J, Frankenberger R. Effect of solvent and rewetting time on dentin adhesion. Quintessence Int 2001;32:385-90.

23.Pereira GDS, Paulillo LA, De Goes MF, Dias CT. How wet should dentin be? Comparison of methods to remove excess water during moist bonding. J Adhes Dent 2001;3:257-60.

24.Ritter AV, Heymann HO, Swift EJ Jr, Perdigão J, Rosa BT. Effects of different re-wetting techniques on dentin shear bond strengths. J Esthet Dent 2000;12:85-96.

25.Mjör IA, SmithMR, FerrariM,Mannocci F (2001) The structure of dentine in the apical region of human teeth. Int Endod J 34(5):346-353. ht t p s://doi.org/10.1046/j.1365 2591.2001.00393.x

26.Pashley DH, Tay FR, Carvalho RM, Rueggeberg FA, Agee KA, Carrilho M, Donnelly A, GarciaGodoy $F$ (2007) Fromdry bonding to water-wet bonding to ethanol-wet bonding. A review of the interactions between dentin matrix and solvated resins using amacromodel of the hybrid layer. Am J Dent 20(1):7-20

27.Gruber YL, Bakaus TE, Gomes OMM, Reis A, Gomes GM(2017) Effect of Dentin Moisture and Application Mode of Universal Adhesives on the Adhesion of Glass Fiber Posts to Root Canal. J Adhes Dent 19(5):385-393. https:// doi.org/10.3290/j.jad.a38998

28.Kosan E, Prates-Soares A, Blunck U, Neumann K, Bitter K. Root canal pre-treatment and adhesive system affect bond strength durability of fiber posts ex vivo. Clinical Oral Investigations. 2021;

29.Feitosa VP, Leme AA, Sauro S, CorrerSobrinho L, Watson TF, Sinhoreti MA, \& Correr AB (2012) Hydrolytic degradation of the resin-dentine interface induced by the simulated pulpal pressure, direct and indirect water ageing Journal of Dentistry 40 (12) 1134-43.

30.Reis A, Albuquerque $M$, Pegoraro $M$, Mattei G, Bauer JR, Grande RH, Klein-Junior CA, Baumhardt-Neto R, \& Loguercio AD (2008) Can the durability of one-step self- etch adhesives be improved by double application or by an extra layer of hydrophobic resin? Journal of Dentistry 36 (5) 309-15.

31.Loguercio AD, \& Reis A (2008) Application of a dental adhesive using the self-etch and etch-and-rinse approach- es: an 18-month clinical evaluation Journal of the American 
Dental Association 139(1) 53-61.

32. Reis A, Leite TM, Matte K, Michels R, Amaral RC, Geraldeli S, \& Loguercio AD (2009) Improving clinical retention of one-step self-etching adhesive systems with an additional hydrophobic adhesive layer Journal of the American Dental Association 140(7) 877-85.

33.Breschi L, Mazzoni A, Ruggeri A, Cadenaro M, Di Lenarda R, \& De Stefano Dorigo E (2008) Dental adhesion review: aging and stability of the bonded interface Dental Materials 24(1) 90-101.

34.Cadenaro M, Antoniolli F, Sauro S, Tay FR, Di Lenarda R, Prati C, Biasotto M, Contardo L, \& Breschi L (2005) Degree of conversion and permeability of dental adhe- sives European Journal of Oral Sciences 113(6) 525-30.

35. Reis A, de Carvalho Cardoso P, Vieira LC, Baratieri LN, Grande RH, \& Loguercio AD (2008) Effect of prolonged application times on the durability of resin-dentin bonds Dental Materials 24(5) 63944.

36.Arrais CA, Giannini M, Nakajima M, Tagami J (2004) Effects of additional and extended acid etching on bonding to caries-affected dentine. Eur J Oral Sci 112:458-64

37.Kerby RE, Knobloch LA, Clelland $N$, et al. Microtensile bond strengths of one-step and selfetching adhesive systems. Oper Dent 2005;30 (2):195-200.

38.Joseph P, Yadav C, Satheesh K, et al. Comparative evaluation of the bonding efficacy of sixth, seventh and eight generation bonding agents: an in vitro study. Int Res J Pharm 2013;4(9):143-47. 